\title{
Objetos de oro y epicampaniforme en la Cova del Gegant. Relaciones en la costa mediterránea de la Península Ibérica durante la Edad del Bronce
}

\author{
Gold artifacts and Late Bell Beaker from Cova del Gegant: Interaction along \\ the Mediterranean coastline of the Iberian Peninsula during Bronze Age
}

\author{
Joan Daura ${ }^{a}$, Montserrat Sanz ${ }^{\mathrm{b}}$, Ignacio Soriano ${ }^{\mathrm{c}}$, Mireia Pedro ${ }^{\mathrm{d}}$, Ángel Rubio ${ }^{\mathrm{e}}$, Mònica \\ Olivaf, Juan Francisco Gibaja $^{\mathrm{g}}$, Ignasi Queralt ${ }^{\mathrm{h}}$, Ramon Álvarez ${ }^{\mathrm{i}}$ y F. Javier López-Cachero ${ }^{\mathrm{d}}$
}

\section{RESUMEN}

En este trabajo se analiza el estrato XXV de la Cova del Gegant (Sitges, Barcelona), adscrito a la Edad del Bronce, y se destaca la problemática cronológica de este período. En este yacimiento encontramos decoraciones epicampaniformes del "Grupo del Nordeste", tradicionalmente atribuidas a un Bronce Antiguo, un osario co- lectivo datado por C14 en el Bronce Medio, ornamentos en ámbar/resina de amplia cronología y dos piezas áureas, muy escasas en el nordeste de la Península Ibérica, que vinculamos con el episodio sepulcral. Las piezas arqueológicas y la serie de dataciones radiocarbónicas nos proporcionan datos importantes sobre las redes de intercambio y los desplazamientos a lo largo de la fachada mediterránea de la Península Ibérica durante la Edad de Bronce.

* Este trabajo es parte del proyecto "El Plistocè Superior a la costa central catalana: paleoambients i ocupació dels neandertals" (2014/100639), financiado por el Servei d'Arqueologia i Paleontologia (Generalitat de Catalunya). Los proyectos 2014SGR-108 y HAR2014-55131 financiaron las analíticas.

a Centro de Arqueologia. Universidade de Lisboa (UNIARQ). Faculdade de Letras. Alameda da Universidade 1600-214 Lisboa, Portugal. Correo e: J. Daura: jdauralujan@campus.ul.pt orcid.org/0000-0002-8364-3655.

b Dpto. de Paleontología, Facultad de Ciencias Geológicas. Universidad Complutense de Madrid. Ciudad Universitaria s/n. 28040 Madrid. Correo e.: msanzborras@ucm.es orcid.org/0000-0002-2263-0121; Centro Universidad Complutense de Madrid - Instituto de Salud Carlos III (UCM-ISCIII) de Investigación sobre la Evolución y Comportamiento Humanos. Avda. Monforte de Lemos 5. 28029 Madrid. España.

c Grupo de Investigación Arqueológica del Nordeste Peninsular (GRANEP) y Dpto. de Prehistòria, Facultat de Filosofia i Lletres. Universitat Autònoma de Barcelona Edifici B. 08193 Bellaterra. España. Correo e.: Ignacio.Soriano@uab.cat orcid.org/0000-00019566-1925.

d Seminari Estudis i Recerques Prehistòriques (SERP). Dept. d' Història i Arqueologia. Facultat de Geografia i Història. Universitat de Barcelona. C/ Montalegre 6-8. 08001 Barcelona. España. Correos e.: mireiapedro@gmail.com orcid.org/0000-0001-5469-9580; xavierlopez@ub.edu orcid.org/0000-0002-3121-4015.

e Laboratorio de Antropología física. Facultad de Medicina. Universidad de Granada. Av. de Madrid 11. 18012 Granada. España. Correo e: a_rubiosalvador@hotmail.com orcid.org/0000-0001-6999-5577.

f Doctora en Prehistoria. Universitat Autònoma de Barcelona. Correo e.: monicaolivapoveda@gmail.com orcid.org/0000-00029148-0569.

g Dpto. de Arqueología y Antropología. Consejo Superior de Investigaciones Científicas - Institución Milá y Fontanals (CSIC-IMF). Carrer de les Egipcíaques 15. 08001 Barcelona. España. Correo e: jfgibaja@imf.csic.es orcid.org/0000-0002-0830-3570.

${ }^{\mathrm{h}}$ Instituto de Diagnóstico Ambiental y Estudios del Agua - Consejo Superior de Investigaciones Científicas (IDAEA-CSIC). C/ Jordi Girona 18-26. 08034 Barcelona. España. Correo e.: ignasi.queralt@idaea.csic.es orcid.org/0000-0002-8790-8382.

${ }^{i}$ Dept. d'Història i Arqueologia. Facultat de Geografia i Història. Universitat de Barcelona. C/ Montalegre 6-8. 08001 Barcelona. España. Correo e.: ralvarez@ub.edu orcid.org/0000-0003-4407-9315.

Recibido 24-X-2016; aceptado 3-XII-2016.

Copyright: (C) 2017 CSIC. Este es un artículo de acceso abierto distribuido bajo los términos de una licencia de uso y distribución Creative Commons Attribution (CC-by) España 3.0. 


\section{ABSTRACT}

This paper presents archaeological layer XXV from Cova del Gegant (Sitges, Barcelona), ascribed to Bronze Age, and focuses on this period's chronological issues. Cova del Gegant yielded Late Bell Beaker pottery featuring a decorative style akin to the "Northeastern Group" (generally ascribed to Early Bronze Age), human remains associated with a collective burial (radiocarbon dated to Middle Bronze Age), amber and/or resin ornaments, and two gold artifacts (very scarce in the NE of Iberian Peninsula). The archaeological artifacts and radiocarbon dating range provide important data concerning the exchange networks and movements along the Mediterranean coastline during Bronze Age.

Palabras clave: Cova del Gegant; Cerámica epicampaniforme; Oro; Edad del Bronce.

Key words: Cova del Gegant; Late Bell Beaker pottery; Gold; Bronze Age.

\section{INTRODUCCIÓN}

Las fases del Bronce Antiguo y Medio en Cataluña presentan una cierta indefinición material como consecuencia de la falta de contextos claros y bien fechados. Dominan los yacimientos caracterizados por estructuras negativas y los contextos funerarios de tipologías muy diversas se reutilizan sucesivamente con enterramientos en general múltiples y con escaso contenido mobiliar (Castro et al. 1996; Soriano 2013). Conscientes de todo esto, en los años 90 se acuñó el concepto de "Bronce Inicial" para definir aquellos contextos de difícil atribución a una fase u otra (Maya y Petit 1995; Maya 1997; Martín et al. 2002).

Esta problemática es perfectamente visible en la Cova del Gegant (Sitges, Barcelona), donde se ha identificado un nivel adscrito cronológicamente al Bronce Inicial, caracterizado por la presencia de un osario colectivo datado por $\mathrm{C} 14$ en el Bronce Medio. Un conjunto material diverso del que destacamos las cerámicas carenadas, la decoración epicampaniforme del "Grupo del Nordeste", los ornamentos en ámbar/resina y dos piezas de oro, sin duda alguna lo más singular, nos permiten reflexionar sobre la secuencia cronológica del Bronce Inicial, así como valorar las relaciones que contemporáneamente se están produciendo en la fachada mediterránea de la Península Ibérica.

\section{LA COVA DEL GEGANT}

La Cova del Gegant (1046'27,33'E, $\left.41^{\circ} 13^{\prime} 24,75^{\prime} \mathrm{N}\right)$ es una cavidad localizada en el extremo meridional del macizo del Garraf (Barcelona) (Fig. 1.1-3). Dispone de dos entradas a escasos metros sobre el nivel del mar pero, al estar actualmente inundadas, se accede a la cavidad a través de una sima vertical situada sobre la Galería Principal (GP). En esta galería de $22 \mathrm{~m}$ de recorrido se han concentrado las excavaciones arqueológicas actuales (GP1+GP2). Casi en paralelo a la GP se disponen dos Galerías Laterales (GL1 y GL2). Un conducto estrecho (GLT) une la GP con la Cova Llarga (CL).

Los trabajos arqueológicos se han centrado fundamentalmente en los niveles pleistocenos (Daura et al. 2010). Sin embargo, el hallazgo de un nivel sepulcral de la Edad del Bronce ha recobrado el interés por la Prehistoria reciente, ya documentada por algunos materiales aislados (Martínez-Moreno et al. 1985; Vega 1987; Martínez-Moreno et al. 1990).

Daura et al. (2010) han definido la estratigrafía del yacimiento. Sitúan los episodios 0 al 3 en el Pleistoceno superior, ca. 49-60 ka BP. Los niveles holocenos están formados por los episodios 4 al 7 . El episodio 4 se corresponde principalmente con el nivel XXV de la Edad del Bronce que ocupa el presente trabajo y cuenta con la presencia del Silo-1 y el Silo-2. El episodio 5 (niveles X y XI) es una formación de playa reciente $(1020 \pm 20 \mathrm{cal}$. AD). El episodio 6 (niveles Ia-f, entre otros) comprende niveles tardo antiguos, medievales y modernos compatibles con la playa del episodio 5 . El episodio 7 se corresponde con la erosión actual o sub-actual del relleno (Fig. 1.4-5).

El nivel XXV se conserva sobre todo en los cuadros $\mathrm{H} 27$ y H28 $\left(\sim 1.8 \mathrm{~m}^{2}\right)$ situados en la parte final de la GP. Probablemente ocupó gran parte de la GP como atestigua un pequeño remanente $\left(<1 \mathrm{~m}^{2}\right)$ conservado en el cuadro I24 que marcaría el límite hacia el sur de la galería. Ambas zonas están desconectadas debido al Recorte-3 (Fig. 1.6), resultado de unos trabajos espeleológicos. El nivel se extiende hacia el norte, en dirección al fondo de la cueva, pero más allá de la zona excavada este nivel se ha preservado como testimonio arqueológico. La mayoría del nivel está compuesto por un sedimento fino de matriz limo-arenosa

Trab. Prehist., 74, N. ${ }^{\circ}$ 1, enero-junio 2017, pp. 149-167, ISSN: 0082-5638

doi: $10.3989 /$ tp.2017.12188 

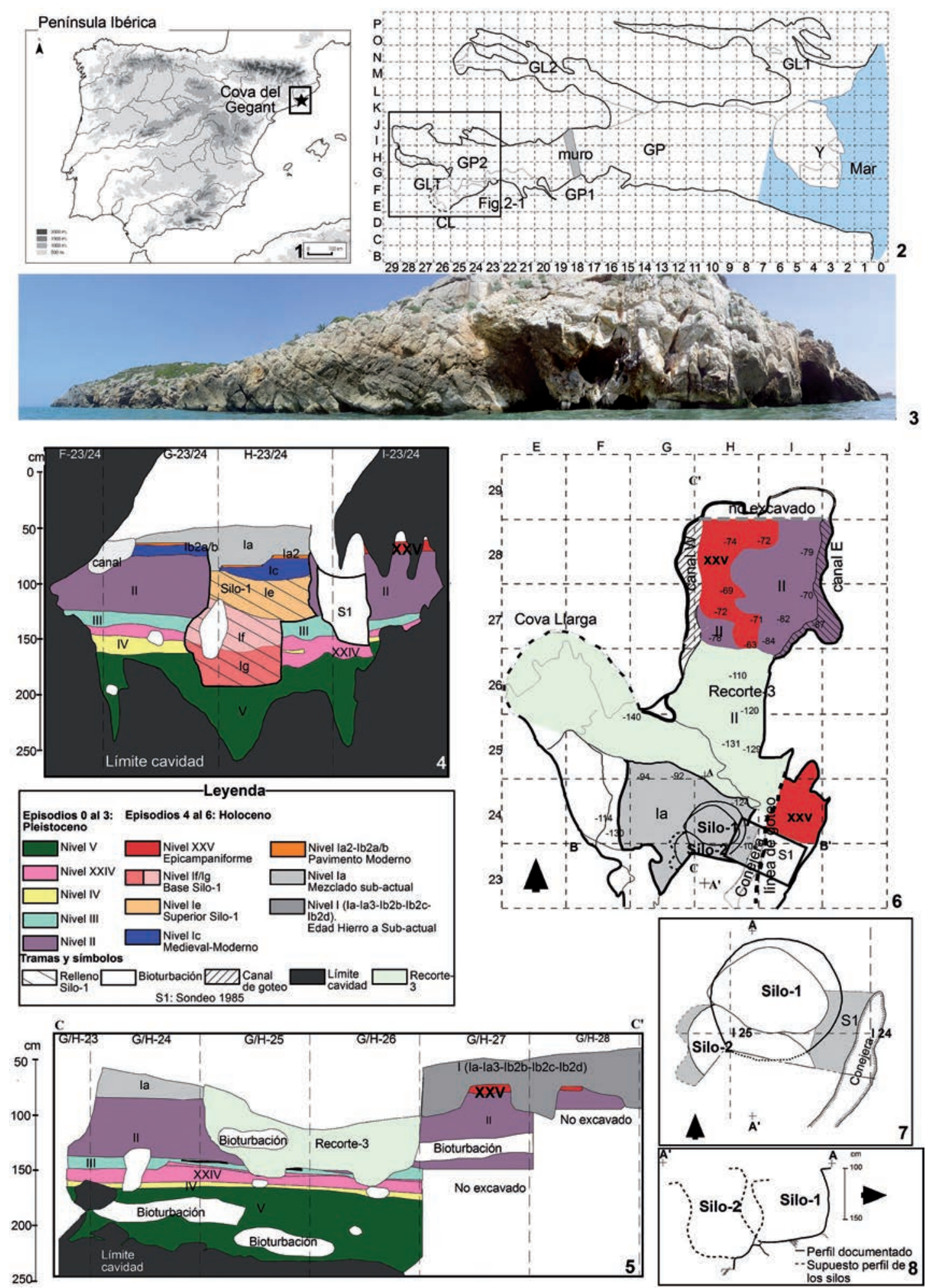

Fig. 1. La Cova del Gegant (Sitges, Barcelona): 1. Situación del yacimiento. 2. Planta de la cavidad. 3. Acceso y vista de la cavidad desde el mar. 4. Sección transversal de la Galería Principal. 5. Sección longitudinal. 6. Planta con ubicación del nivel XXV y de los silos. 7. Planta de los silos. 8. Sección de los silos. En color en la edición electrónica. 
y textura blanda que ha facilitado su exposición a los procesos postdeposicionales. Los fósiles directores cerámicos que contiene lo ubican en la Edad del Bronce.

El Silo-1 se ubica en el cuadro H24 y el Silo-2 en el cuadro G23 (Fig. 1.4, 6-8). Ambos están afectados por la erosión marina en el lado sur. Además el sondeo S1 de 1985 cortó el Silo-1. Probablemente ambos silos se entrecruzaron, aunque no ha sido posible definir la secuencia estratigráfica. Solo se ha preservado el relleno del Silo-1 con subniveles distinguidos por la cantidad de guijarros. Los subniveles If y Ig (episodio 4) forman la base. Indican la fase de amortización con material homogéneo consistente en cerámicas prehistóricas de la Edad de Bronce y huesos humanos. Los subniveles que forman el techo del relleno (Ie y Ie2) y el interior y el suelo de la galería (Ic y Ia2) son de época medieval-moderna. Esta secuencia de rellenos nos lleva a pensar que el silo es, en parte, posterior al nivel XXV, sin embargo no hay relación estratigráfica directa.

Finalmente, señalamos que la sedimentación del nivel I (episodio 6), formada por guijarros de playa, fue precedida de una fase erosiva que implicó el retrabajamiento y la resedimentación de la parte más externa del nivel XXV, cuyo material arqueológico decrece en la distintas sub-unidades del nivel I, a medida que estratigráficamente nos alejamos de este nivel XXV y nos acercamos al techo del nivel I.

Este estudio se ha centrado en el contenido arqueológico del nivel XXV y en los elementos hallados en el nivel I cuyas características tipológicas, estilísticas o cronológicas indicaban su procedencia del nivel XXV.

\section{RESTOS ÓSEOS HUMANOS Y CRONOLOGÍA}

Los restos óseos $(\mathrm{NR}=1728)$ se encuentran en un estado de conservación deficiente siendo los más representados los dientes y los huesos cortos de la mano y el pie (Fig. 2). Su estado de fragmentación impide, en la mayoría de los casos, la observación y el análisis correcto de los mismos. Esto ha favorecido el empleo de métodos para establecer el sexo y la edad de los individuos más aproximativos que los convencionales. La determinación de la edad para los subadultos sigue a Ubelaker (1978) y Schaefer et al. (2009), para la estimación del sexo en adultos a Viciano et al. (2013) y Alemán et al. (1997) y para la edad a Ișcan et al. (1984, 1985) y Brothwell (1989).

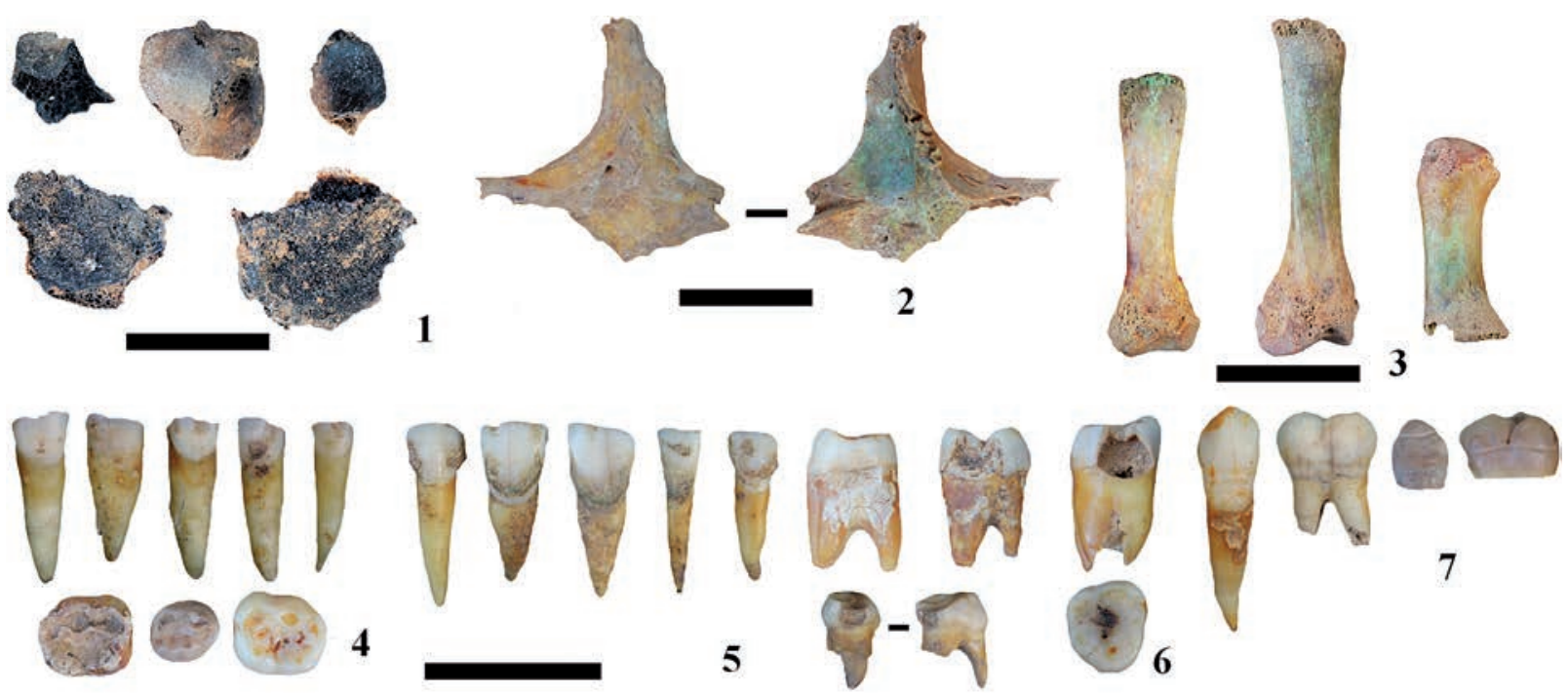

Fig. 2. Restos humanos de la Cova del Gegant (Sitges, Barcelona): 1. Huesos carbonizados. 2. Malar izquierdo con coloración en su parte posterior. 3. Metacarpianos izquierdos del individuo VIII. 4. Desgaste en dientes permanentes y dientes deciduos. 5. Dientes con sarro. 6. Dientes permanentes y deciduo con caries. 7. Dientes con bandas de hipoplasia. Escala $2 \mathrm{~cm}$.

Trab. Prehist., 74, N. ${ }^{\circ}$ 1, enero-junio 2017, pp. 149-167, ISSN: 0082-5638

doi: $10.3989 /$ tp.2017.12188 
El conjunto consta de un mínimo de 19 sujetos (Tab. 1): 1 neonato, 6 infantiles (grupo I), 3 infantiles (grupo II), 1 juvenil y 8 adultos. En el grupo de adultos hay 4 varones, 2 mujeres y 2 indeterminados. Se observa la elevada mortalidad infantil (36,8\% en la primera infancia), esperada para este tipo de poblaciones. La esperanza media de vida en la edad adulta también es baja: ningún individuo superaría los 40 años y más de la mitad no alcanzaron los 30 años.

La coloración verdosa registrada en un hueso cigomático y en los metacarpianos de la mano izquierda de un individuo infantil de unos 7 años es atribuible a corrosión metálica por contacto con un objeto de base cobre (Fig. 2.3). Cabe destacar también algunos huesos que no se quemaron en fresco $(0,4 \%)$, práctica que no parece guardar relación con un ritual funerario realizado (Fig. 2.1). Entre ellos, se ha identificado una vértebra dorsal (Fig. 2.2) de un individuo adulto y una epífisis distal de peroné de un subadulto.

El desgaste dentario es acentuado en dos individuos adultos de la población. El que los desgastes sean muy bajos en el resto de los dientes podría estar relacionado con la baja edad de los adultos (Fig. 2.4). El Individuo 12 tiene cálculo dental (sarro) en todos sus dientes. Se ha identificado la presencia de caries en los molares de al menos tres adultos y en un primer molar deciduo del Individuo 7, subadulto. Esto unido al

\begin{tabular}{|c|c|c|c|c|c|c|c|c|c|c|c|}
\hline Indiv. & Nivel & Sexo & $\begin{array}{c}\text { Rango } \\
\text { de edad }\end{array}$ & $\begin{array}{c}\text { Edad } \\
\text { estimada }\end{array}$ & Muestra & Parte & $\begin{array}{c}\text { Código } \\
\text { Laboratorio }\end{array}$ & $\delta 13$ & Edad BP & $\begin{array}{c}2 \sigma \text { cal } \\
\text { años BC }\end{array}$ & $\begin{array}{c}2 \sigma \text { cal } \\
\text { años BP }\end{array}$ \\
\hline 1 & XXV & - & Neonato & $3-6$ & & & & & & & \\
\hline 2 & XXV & - & Infantil I & $1-1,5$ & & & & & & & \\
\hline 3 & XXV & - & Infantil I & 2 & & & & & & & \\
\hline 4 & XXV & - & Infantil I & 3 & & & & & & & \\
\hline 5 & XXV & - & Infantil I & $3,5-4$ & \multirow{3}{*}{$\begin{array}{l}\text { CG13- } \\
4418\end{array}$} & \multirow{3}{*}{$\begin{array}{l}\text { Segundo } \\
\text { molar } \\
\text { inferior } \\
\text { deciduo }\end{array}$} & \multirow{3}{*}{ OxA-29612 } & \multirow{3}{*}{17,8} & \multirow{3}{*}{$3225 \pm 27$} & \multirow{3}{*}{$\begin{array}{l}1603-1584 \\
(4,3 \%) \\
1544-1430 \\
(91,1 \%)\end{array}$} & \multirow{3}{*}{$\begin{array}{l}3552-3522 \\
(4,3 \%) \\
3492-3379 \\
(91,1 \%)\end{array}$} \\
\hline 6 & XXV & - & Infantil I & 4 & & & & & & & \\
\hline 7 & XXV & - & Infantil I & $5-6$ & & & & & & & \\
\hline 8 & XXV & - & Infantil II & 7 & & & & & & & \\
\hline 9 & XXV & - & Infantil II & 9 & & & & & & & \\
\hline 10 & XXV & - & Infantil II & $11-12$ & & & & & & & \\
\hline 11 & XXV & - & Juvenil & 15 & & & & & & & \\
\hline 12 & XXV & $0^{\pi}$ & Adulto & $24-28$ & & & & & & & \\
\hline 13 & XXV & $0^{x}$ & Adulto & $35-40$ & & & & & & & \\
\hline 14 & XXV & q & Adulto & $20-23$ & & & & & & & \\
\hline 15 & XXV & $0^{7}$ & Adulto & $21-25$ & & & & & & & \\
\hline 16 & XXV & $0^{7}$ & Adulto & $25-30$ & & & & & & & \\
\hline 17 & XXV & \% & Adulto & $25-30$ & $\begin{array}{l}\text { CG10- } \\
3367\end{array}$ & $\begin{array}{l}\text { Segundo } \\
\text { premolar } \\
\text { superior }\end{array}$ & Beta-312860 & 19,3 & $3270 \pm 30$ & $\begin{array}{l}1623-1496 \\
(92,7 \%) \\
1475-1460 \\
(2,7 \%)\end{array}$ & $\begin{array}{l}3445-3572 \\
(92,7 \%) \\
3409-3424 \\
(2,7 \%)\end{array}$ \\
\hline 18 & $\mathrm{Ib} 2 \mathrm{~d}$ & - & Adulto & $21-40$ & \multirow{2}{*}{$\begin{array}{l}\text { CG09- } \\
2401\end{array}$} & \multirow{2}{*}{$\begin{array}{l}\text { Canino } \\
\text { superior }\end{array}$} & \multirow{2}{*}{ Beta-312861 } & \multirow{2}{*}{18,9} & \multirow{2}{*}{$3200 \pm 30$} & \multirow{2}{*}{$1526-1417$} & \multirow{2}{*}{$3366-3474$} \\
\hline 19 & Ia & - & Adulto & $21-40$ & & & & & & & \\
\hline
\end{tabular}

Tab. 1. Restos humanos de la Cova del Gegant (Sitges, Barcelona), agrupados según número de individuos, nivel de procedencia, sexo atribuido, rango de edad y edad estimada (Individuo 1 en meses, el resto en años). Dataciones por radiocarbono calibradas mediante OxCal 4.3 (Bronk Ramsey 2009) (http://c14.arch.ox.ac.uk/) según la curva Intcal13 (Reimer 2013). 
sarro podría estar relacionado con una dieta rica en hidratos de carbono (Fig. 2.5-6).

Entre los marcadores relacionados con el estrés medioambiental se ha registrado hipoplasia del esmalte en dos subadultos y tres adultos: el $26,3 \%$ de los inhumados (Fig. 2.7). Las bandas de hipoplasia sugieren que los individuos sufrieron uno o varios episodios carenciales durante su infancia, quizás provocados por déficits nutricionales, infecciones y otras enfermedades. Los episodios que han podido ser estimados suceden entre el segundo y el cuarto año de edad.

Tres muestras de tres individuos diferenciados se han fechado para determinar el rango cronológico de los restos humanos (Tab. 1): Individuo 5-7 y Individuo 17 del nivel XXV e Individuo 18 o 19 del nivel I. Mediante el software Calib 7.0 (Ward and Wilson 1978; Reimer 2013) se ha realizado el test Chi-2 y un Test-T y los 3 resultados retornan $\mathrm{t}=2.81\left(\chi^{2}(0.05)=5.99\right.$ con 2 grados de libertad). Es decir, las tres muestras representan un episodio cronológico homogéneo que nos sitúa en un horizonte de $\sim 1600-1400$ cal BC.

\section{MATERIALES ARQUEOLÓGICOS}

El conjunto cerámico, muy fragmentado, está compuesto por 71 restos recuperados en el nivel XXV. Se adscriben a 9 vasos, determinados a partir de las formas de los bordes, analizados a nivel macroscópico y tipológico (Dedet y Py 1975). Atribuimos también a este conjunto algunos fragmentos procedentes del nivel I (episodio 6) que en algunos casos remontan parcialmente entre sí. A este conjunto, hay que añadir un último vaso (Vaso 10 - Fig. 3.3) procedente del nivel I y compatible tipológicamente con el conjunto de vasos incluidos en el nivel XXV.

En 4 vasos se ha podido reconstruir parcialmente el perfil. Destaca un gobelet (Vaso 1 - Fig. 3.1) con decoración epicampaniforme definido a partir de una veintena de fragmentos de factura cuidadosa y esmerada en la pasta y las superficies. Los motivos incisos e impresos pseudoungulados o de media caña se disponen en líneas horizontales y verticales. Sobre el labio se observa una serie de impresiones regulares. Presenta claras similitudes con el "Grupo del Nordeste" tanto en el perfil acampanado, coincidente con la forma 5 de Maya y Petit (1986), como en la decoración, si bien en este caso faltan las típicas guirnaldas y zigzags con flecos.

Los 9 vasos restantes se agrupan en tres conjuntos tipológicos diferentes. Hay 5 vasos (Vasos $3,6,7,8,9)$ con perfil en $\mathrm{S}$, el borde exvasado y un acabado bruñido-pulido. Son lisos, salvo el Vaso 8 que presenta impresiones regulares en el labio (Fig. 3.6). Los Vasos 2, 4 y 5 tienen un perfil bitroncocónico con carena marcada, borde exvasado y superficie exterior bruñida-pulida (Fig. 3.5, 3.4 y 3.2). Por último, el Vaso 10 es troncocónico, liso y con un pezón bajo el labio (Fig. 3.3).

La única pieza lítica recuperada en el nivel XXV es un fragmento medial de lámina de sílex (Fig. 3.7) con una única arista central, que ha estado retocada en todo su perímetro. El retoque de los laterales es denticulado (Fig. 3.8 y 10) y el de los extremos abrupto en forma de truncadura (Fig. 3.9). El análisis microscópico demuestra que ambos filos fueron utilizados para segar cereales mientras que el micropulido, muy intenso, puede atribuirse al tiempo invertido en su uso.

Las zonas pulidas están salpicadas de estrías y áreas picoteadas por la abrasión (Fig. 3.11-12), quizá, por haber usado la hoz cerca de la tierra en una siega baja. La intensidad del micropulido no es homogénea en el interior de todas las melladuras que conforman el denticulado. Esto indicaría que el objetivo de este retoque fue afilar de nuevo la zona activa y que los afilados se distanciaron en el tiempo, dado el desarrollo heterogéneo del micropulido en el interior de las melladuras.

Las truncaduras (Fig. 3.9), por su parte, debieron servir para romper la curvatura de la lámina y así facilitar la inserción de la pieza en una hoz compuesta por varios soportes. La distribución del micropulido a lo largo de los filos muestra una delineación ligeramente curva (Fig. 3.7). Esta sería la parte que quedaría fuera de la zona enmangada o cubierta por el mastique.

Una docena de restos forman el conjunto de adornos no metálicos: 4 cuentas están realizadas en malacología marina, 3 en lignito-azabache, 2 en ámbar o resina cristalizada, 1 en coral, 1 se corresponde con un fragmento de colmillo de suido con desgaste natural y finalmente 1 se corresponde con una Cypraea. Proceden todas ellas del nivel XXV salvo dos de las cuentas circulares (Fig. 4.2 y 4) y la Cypraea (Fig. 4.10). 

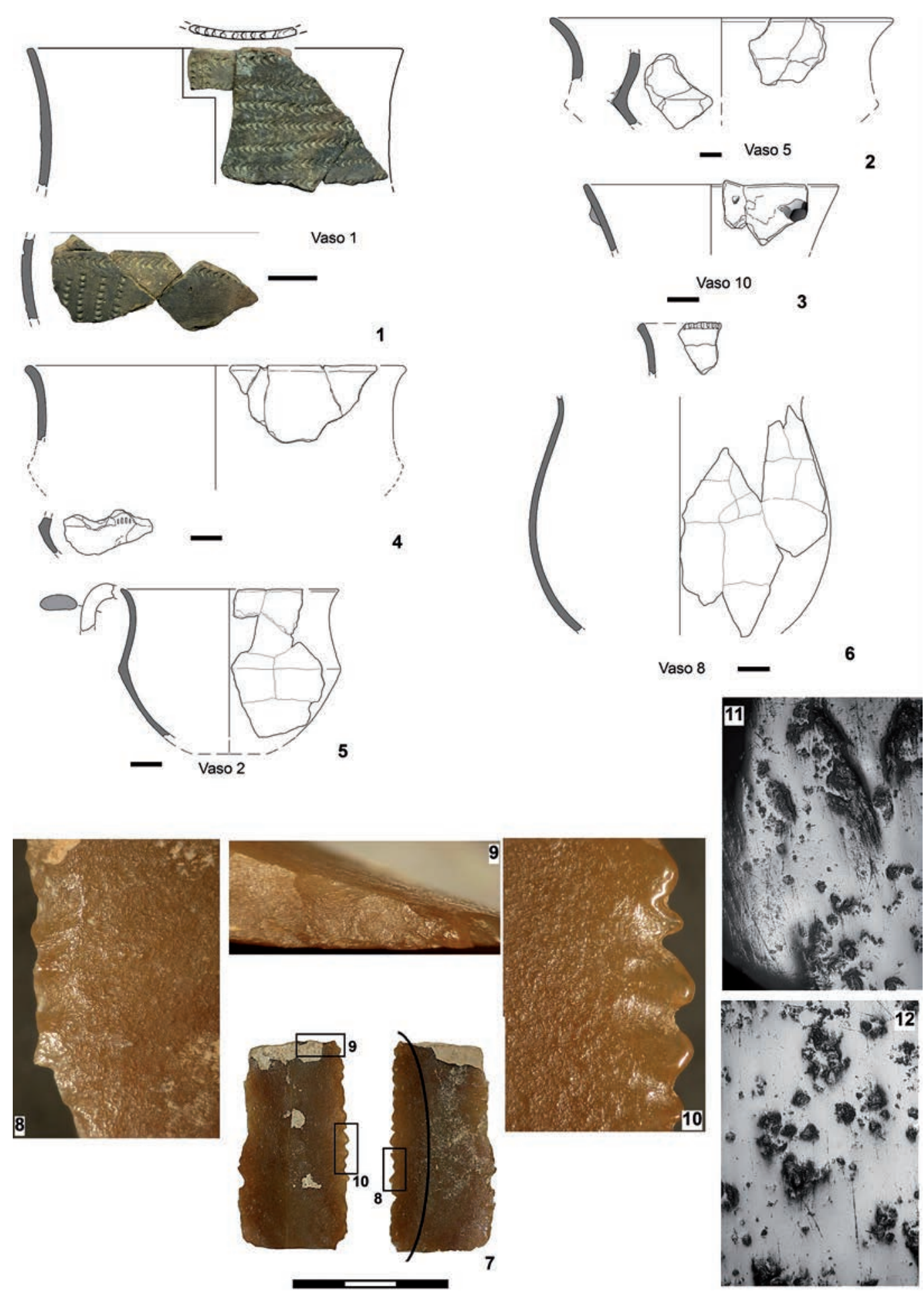

Fig. 3. Restos cerámicos y líticos de Cova del Gegant (Sitges, Barcelona): 1-6. Principales vasos cerámicos, el 1 tiene decoración epicampaniforme. Escala $2 \mathrm{~cm}$. 7. Lámina denticulada de sílex empleada por ambos lados para segar cereales. El límite curvado reflejado en la cara ventral (7) sería el límite de distribución del micropulido y, por tanto, de la zona enmangada. Escala $3 \mathrm{~cm}$. Las fotos microscópicas a 100X (11 y 12) corresponden a la ampliación de la 8 y 10 , respectivamente. 


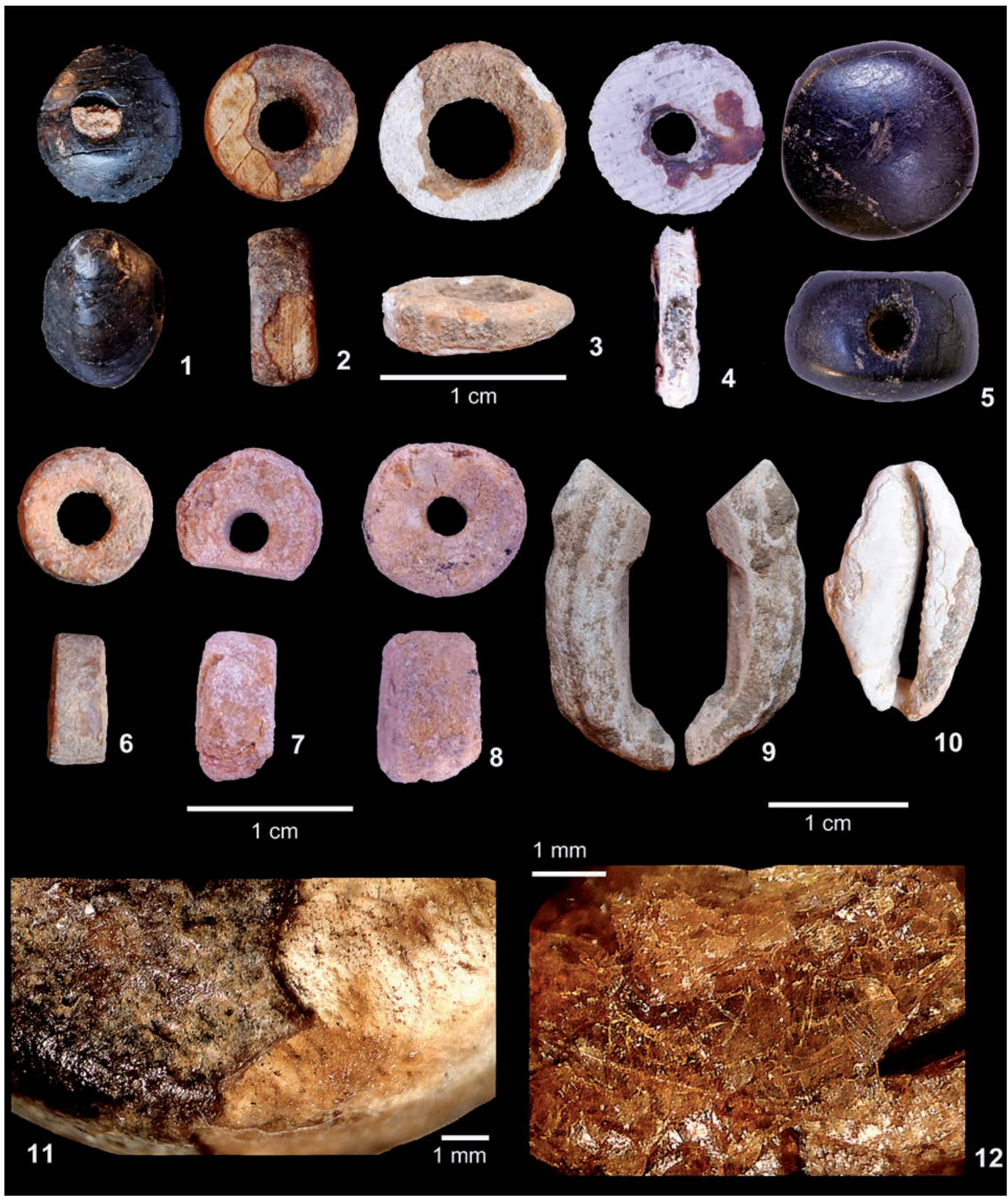

Fig. 4. Conjunto de adornos de la Cova del Gegant (Sitges, Barcelona): 1. y 5. Cuentas de azabache. 2-4. y 6. Cuentas de concha (11. detalle del revestimiento superficial de resina). 7-8. Cuentas de ámbar (12. detalle de la 7). 9. Coral con pulido superficial; 10. Cypraea. 
Las cuentas sobre concha de la familia Cardiidae son circulares (Fig. 4.2-4 y 6). Tienen un orificio central de suspensión o inserción abierto por perforación rotativa concéntrica unipolar o, en un caso, bipolar. Todas están bañadas o recubiertas por una resina que les da un color marrón y que oculta las costillas de la concha salvo donde el revestimiento se ha perdido. Se han observado trazas y marcas de uso por rozamientos reiterados en sus bordes y contornos. La Cypraea, quizás empleada como adorno (Fig. 4.10), ha perdido la superficie original y sólo se conserva la zona de los labios y dientes erosionada. También se ha documentado otro gasterópodo marino (Hetaplex trunculus) perforado de forma natural en la última vuelta, y finalmente, un opérculo con una perforación intencional por abrasión procedentes del nivel I, que no se han podido adscribir al conjunto de la Edad de Bronce.

Las 3 cuentas de lignito-azabache son de color negro intenso y algo frágiles. Una es de contorno circular, base plana, superficie apuntada y una perforación bipolar transversal que originó dos orificios de inserción. Está pulida por abrasión, como deducimos de las numerosas estrías de distribución irregular y de los planos de abrasión hechos antes de la perforación. Se observan trazas de roce en los contornos debido a su uso reiterado. Otra, discoidal (Fig. 4.5), tiene dos orificios de inserción en sus extremos conectados y realizados de manera bipolar. El pulido de las superficies dejó líneas en todas direcciones salvo en los contornos donde son paralelas. También presenta planos previos por abrasión en la zona de los orificios. La tercera cuenta es ovoide (Fig. 4.1) con superficie muy pulida por abrasión y una perforación rotativa concéntrica bipolar que la atraviesa totalmente, dando lugar a los dos orificios de inserción. En uno se observan hasta dos intentos de perforación mediante trépano.

Las 2 cuentas discoidales en ámbar o resina cristalizada son de color marrón claro translúcido. Una está muy fragmentada (Fig. 4.7 y 12), lo que no impide observar que el orificio central se realizó por perforación concéntrica bipolar. La otra está completa y tiene las mismas características (Fig. 4.8). La perforación central se hizo de forma directa unipolar. Finalmente hay un fragmento de coral rosado (Fig. 4.9) con evidencias de pulido en la superficie.
Se han recuperado dos piezas de oro completas procedentes del nivel XXV (Fig. 5) del tipo denominado tutulus (singular) o tutuli (plural) (Perea 1991). Son adornos de suspensión indirecta efectuados a partir de una lámina de oro. $\mathrm{Su}$ morfología trompetiforme o abocinada finaliza en un disco ligeramente sobreelevado en el borde. Estas piezas muy reducidas (peso $\sim 1 \mathrm{~g}$ ) y casi idénticas generan por su propia estructura un orificio o tubo central vertical. Una en perfecto estado (Fig. 5.4-6) presenta el borde del disco decorado mediante un puntillado lineal que forma una única línea. La otra carece de decoración (Fig. 5.1-3) y su parte superior está aplastada en parte $\mathrm{y}$ con alguna rotura.

Ambos objetos han sido analizados mediante fluorescencia de rayos X (FRX) con un espectrómetro de micro-FRX (Helmut Fischer ${ }^{\mathrm{TM}}$, modelo XDV-SD) en los laboratorios del IDAEA-CSIC (Tab. 2). La instrumentación dispone de un tubo de tungsteno como fuente primaria de excitación. Los análisis se realizaron con un voltaje de $50 \mathrm{kV}$ y tensión de $128 \mu \mathrm{A}$, utilizando un filtro primario de aluminio para reducir el fondo espectral y evitar interferencias con las líneas analíticas procedentes del tubo de rayos $\mathrm{X}$ utilizado. Para este estudio se hizo una calibración específica con seis materiales certificados de referencia internacionales $^{1}$ abarcando el rango de $33 \%$ a $100 \%$ de oro en la aleación. Los fundamentos del análisis con dicha instrumentación (Roessiger y Nensel 2003), así como la idoneidad de su aplicación en joyería (Jurado-López et al. 2006) están ampliamente descritos.

El oro para la conformación de objetos decorativos o de orfebrería puede tener un origen primario (filones o inclusiones en rocas encajantes) o secundario (aluvial). El primario suele tener una composición química más variada que el aluvial. Además normalmente a mayor grado de transporte, mayor es el contenido de la ley en el oro como consecuencia del desgaste sufrido, ya que el oro es más insoluble que el resto de elementos presentes en su composición. Los elementos minoritarios más comunes que se le asocian de manera natural son plata y cobre (Raub 1995),

\footnotetext{
${ }^{1}$ Helmut Fischer GmbH 2012. "Primary reference standards for precious metal analysis (gold alloys)". Traceability Rep. SD 2012 04. http://www.helmut-fischer.es/fileadmin/user_upload [20-X-2016].
} 


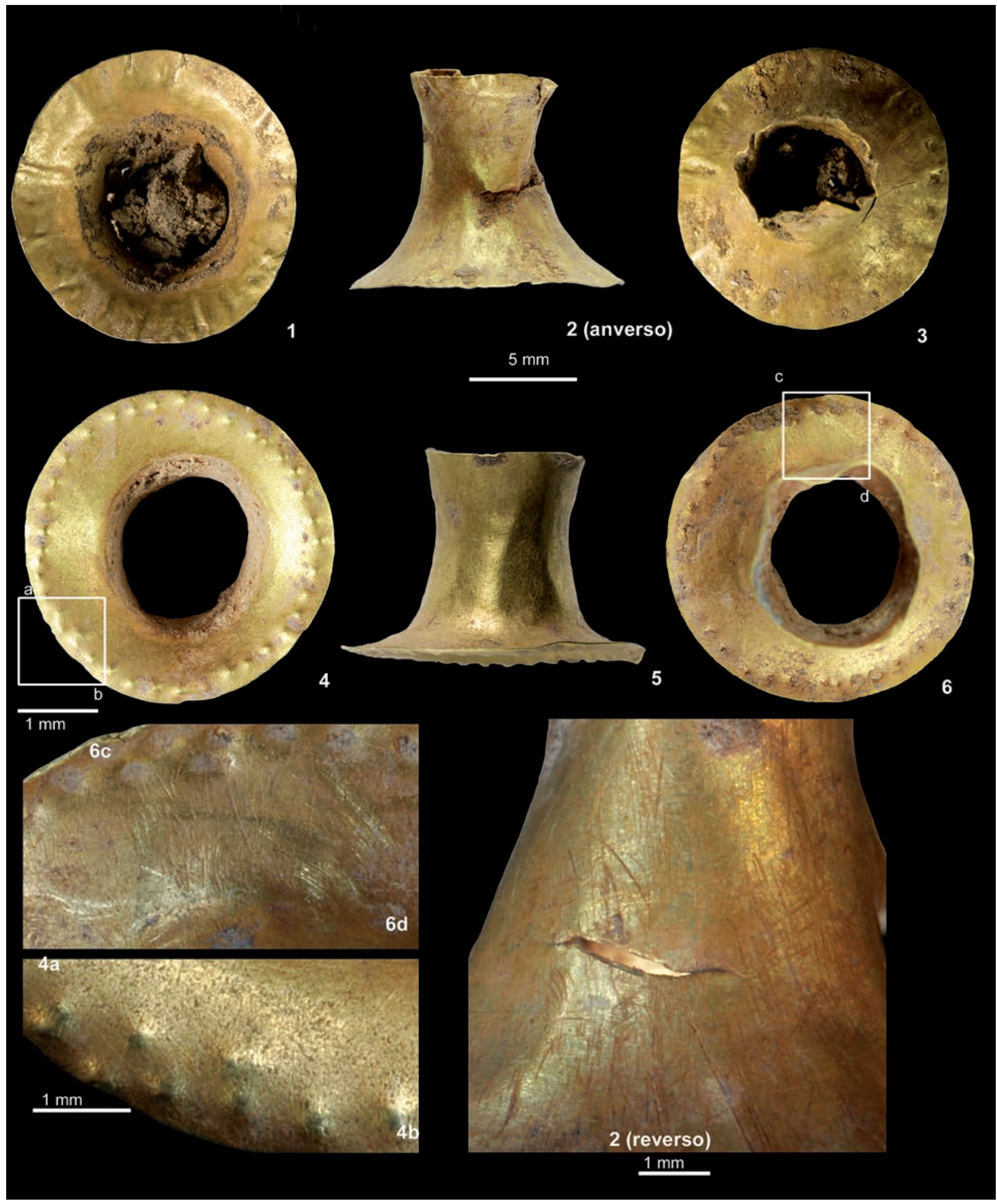

Fig. 5. Tutuli de oro de la Cova del Gegant (Sitges, Barcelona): 1-3 Pieza sin decoración (núm. 4456) y detalle del estriado de manufactura (2 reverso). 4-6 Pieza decorada (núm. 4457) y detalles del puntillado lineal (4a,b) y de las estrías del pulido final. 


\begin{tabular}{|l|l|l|c|l|l|l|}
\hline \multirow{2}{*}{} & \multicolumn{3}{|c|}{ Tutulus 4456 (Figs. 5.1-3) } & \multicolumn{3}{|c|}{ Tutulus 4457 (Figs. 5.4-6) } \\
\cline { 2 - 7 } & $\begin{array}{c}\text { Au } \\
\mathbf{( \% )}\end{array}$ & $\begin{array}{c}\mathbf{A g} \\
\mathbf{( \% )}\end{array}$ & $\begin{array}{c}\mathbf{C u} \\
\mathbf{( \% )}\end{array}$ & $\begin{array}{c}\text { Au } \\
\mathbf{( \% )}\end{array}$ & $\begin{array}{c}\mathbf{A g} \\
\mathbf{( \% )}\end{array}$ & $\begin{array}{c}\mathbf{C u} \\
\mathbf{( \% )}\end{array}$ \\
\hline Lectura 1 & 80,8 & 17,3 & 1,86 & 86,5 & 13,0 & 0,452 \\
\hline Lectura 2 & 80,8 & 17,3 & 1,86 & 86,5 & 13,1 & 0,426 \\
\hline Lectura 3 & 81,5 & 16,6 & 1,81 & 86,6 & 13,0 & 0,386 \\
\hline Lectura 4 & 80,2 & 17,9 & 1,94 & 86,8 & 12,9 & 0,338 \\
\hline Lectura 5 & 79,9 & 17,9 & 2,16 & 86,8 & 12,8 & 0,421 \\
\hline Media & 80,64 & 17,41 & 1,946 & 86,64 & 12,95 & 0,405 \\
\hline $\begin{array}{l}\text { Desviación } \\
\text { Estándar }\end{array}$ & 0,620 & 0,541 & 0,126 & 0,137 & 0,116 & 0,044 \\
\hline Rel. D.E. (\%) & 0,77 & 3,11 & 6,48 & 0,16 & 0,89 & 10,87 \\
\hline Rang0 & 1,60 & 1,35 & 0,308 & 0,290 & 0,273 & 0,114 \\
\hline Lectura Mínima & 79,9 & 16,6 & 1,86 & 86,5 & 12,8 & 0,338 \\
\hline Lectura Máxima & 81,5 & 17,9 & 2,16 & 86,8 & 13,1 & 0,452 \\
\hline Tiempo Lectura & $100 \mathrm{~s}$ & & & $100 \mathrm{~s}$ & & \\
\hline
\end{tabular}

Tab. 2. Análisis de los dos tutuli de la Cova del Gegant (Sitges, Barcelona) mediante espectrometría de fluorescencia de rayos $\mathrm{X}$.

presentes en porcentajes inferiores al $25 \%$ para $\mathrm{Ag}$ y $1 \%$ para $\mathrm{Cu}$. Por encima debe considerarse fruto de una aleación artificial (Montero y Rovira 1991) o ser un oro próximo a filones primarios (electrum, con contenidos hasta un $35-45 \%$ de plata más cobre). Según los resultados del análisis el oro utilizado en la Cova del Gegant es de tipo aluvial. Habitualmente, las pepitas o pajuelas áureas que se encuentran en el mismo punto de un curso fluvial tienen idéntica composición química, fruto del mismo grado de transporte. Las diferencias en el contenido de oro entre ambos tutuli podría sugerir el empleo de pepitas procedentes de distintos placeres auríferos sin embargo es muy difícil relacionar oro geológico y objetos manufacturados (Pernicka 2014a, 2014b).

El proceso de fabricación de las piezas se ha determinado por observación mediante lupa binocular. Consiste en tres etapas: preparación de la lámina, obtención morfológica del objeto y decoración. Una vez recogidas las pepitas de oro, se funden para eliminar las inclusiones presentes de forma natural. Después se vierten en un molde o se dejan solidificar en el propio crisol hasta lograr un botón de fundición. El producto resultante se trabaja mediante sucesivas fases de batido, marti- lleado, recocido y pulido, obteniendo una lámina que se recorta según las dimensiones deseadas. En nuestro caso los bordes muestran un corte muy regular, realizado de un solo tajo.

Tras estas fases comienza la configuración del tutulus. Se podría plantear que la pieza se fabricara perforando el botón de fundición y estirando el metal en caliente hasta darle su forma definitiva por batido o presión. Sin embargo, este proceso no nos parece el más adecuado ya que ni la morfología de la pieza permite estirar tanto el metal, ni se conseguiría un grosor homogéneo de la lámina. Además no hay traza alguna del proceso de perforación del botón. Por ello consideramos más plausible su fabricación a partir de una lámina, práctica conocida desde el Neolítico Final (Murillo-Barroso et al. 2015). La lámina se embute en un alma (posiblemente de madera) con la morfología deseada, lo que genera líneas de deformación o pliegues en la superficie interior y exterior de la pieza. Después se eliminan tanto éstas como la línea de juntura de ambos extremos de la lámina, como se ha documentado en otros casos (Soriano et al. 2012). El método más plausible para ello es la combinación de bruñido, recocido y pulido final para resaltar el brillo del oro. La superficie interior de las piezas del Cova del Gegant está compuesta por un campo de estrías desordenadas y caóticas (Fig. 5), que concuerda con el proceso final de pulido. Este campo se observa al exterior de uno de los tutulus (Fig. 5.4 y 5.6) pero no del otro (Fig. 5.1 y 5.3) que presenta estrías paralelas, perpendiculares al eje de la pieza o algo oblicuas, así como abundantes pliegues, probablemente vinculados a la cinemática del útil de frente activo liso empleado en el embute. Estas huellas han sido eliminadas del otro tutulus por el pulido final. En ambas piezas es invisible la línea de unión de los extremos de la lámina.

En último lugar la decoración se realiza fuera del alma y de forma manual. La variación máxima de $\sim 1 \mathrm{~mm}$ entre los tutuli apunta al empleo de una misma matriz. Sabemos que la ornamentación se realizó a posteriori porque solo uno tiene el puntillado lineal (Fig 5.4). Los puntos se hicieron presionando desde el exterior al interior del borde. La distancia entre los puntos no es regular y tampoco se detectan las agrupaciones de puntos, indicativas del empleo de matrices de estampación. Estos datos sugieren un puntillado manual, empleando un útil de ápice romo (si fuera apunta- 
do perforaría la lámina) sobre madera dura, hueso, asta o incluso metal. La destreza del orfebre en esta pieza es discutible: en un tramo la línea de puntos se solapa sobre sí misma, generando dos líneas puntilladas (Fig. 5.4-6).

Las notorias diferencias en el proceso de producción y acabado de los tutuli pueden atribuirse a: (i) que fueran fabricadas por distintos orfebres, (ii) que su funcionalidad difiriera o bien (iii) que el no decorado estuviera sin acabar. Faltan datos para decidir que alternativa es la más acertada. Sin embargo consideramos improbable que hubiera más de un orfebre en activo sincrónicamente por a) la similitud métrica y morfológica de los tutuli, b) la ausencia de las fases de fabricación de pulido final y decoración en uno, c) su procedencia del mismo contexto y d) la rareza de estos adornos en el ámbito del noreste de la Península Ibérica.

Se han emitido diferentes y variadas hipótesis sobre la funcionalidad de este tipo de objetos. Inequívocamente su finalidad ornamental pudo ir cambiando en sucesivas reutilizaciones. Para algunos investigadores son colgantes o botones ya que muchos ejemplares presentan perforaciones transversales para su engarce (Soler García 1987). Otros los interpretan como extremos de colgantes o pseudo/tampones distales de objetos decorativos o suntuarios, tipo torques, orejeras o apliques de vestimentas ya que otros ejemplares carecen de perforaciones y tienen huellas de su embutido sobre otro objeto (Rovira 1996). Idéntica interpretación se ha propuesto a partir de las que sí tienen perforaciones que servirían para reforzar la sujeción del tutulus con un elemento medial, aunque, según su número, darían quizás lugar a objetos de distinto tipo ${ }^{2}$. Hay quien los ha definido de forma más genérica como revestimientos de otros objetos de madera, cuero o tela, asumiendo su polifuncionalidad. Esta se basa en la presenciaausencia de perforaciones y en la constatación de que, según los casos, el uso es visible en la superficie externa o interna (Perea 1991). Finalmente pudieron servir como dilatadores de oreja, uso propuesto para los carretes o cuentas hiperbólicas del grupo argárico, similares a los tutuli. Las piezas argáricas son tanto de oro como de plata y,

\footnotetext{
2 Barciela, V. 2015: El lenguaje de los adornos: tecnología, uso y función. Adornos personales de la Edad del Bronce en Alicante y Albacete. Tesis Doctoral inédita, Universidad de Alicante. Alicante.
}

a veces como en el reciente ejemplar recuperado en La Almoloya, el borde del disco está decorado mediante puntillado lineal (Lull et al. 2015).

\section{DISCUSIÓN}

La Cova del Gegant funcionó como un lugar de enterramiento colectivo donde se depositaron un mínimo de 19 individuos en un marco cronológico aproximado entre el 1600 y el 1400 cal. BC. Los restos humanos carecen de conexión anatómica, posiblemente por remociones postdeposicionales, algo habitual en enterramientos de características similares (Armentano y Malgosa 2003). Uno de los niños de 7 años muestra una coloración verdosa indicativa de que, en origen, su cuerpo estuvo en relación con algún objeto de base cobre. Al no haberse recuperado ninguno, no podemos discernir ni su tipología, ni si se asociaba al cuerpo o bien el tinte era post-deposicional y debido a su proximidad accidental con un objeto metálico.

La cronología de la Cova del Gegant coincide en el tiempo con un proceso de transformación de las comunidades del noreste de la Península Ibérica durante el Bronce Inicial, cuando a partir de $1850-1650$ cal BC se detectan algunas disimetrías sociales en las prácticas funerarias. Ésta se caracterizan por la aparición de panteones familiares, la deposición de animales o depósitos culturales y la aparición de algunas tumbas individualizadas con ajuares metálicos (Soriano 2013).

El hallazgo de unos cuantos huesos quemados corresponde a una alteración constatada de forma esporádica desde el Neolítico Antiguo, si bien suelen ser muestras procedentes de excavaciones antiguas (Agustí y Mercadal 2002). En contextos del Calcolítico y del Bronce Inicial esta alteración se documenta parcialmente (Capuzzo y Barceló 2015). Sin embargo en la Cova del Gegant hay que relacionar esta cremación con alteraciones postdeposicionales sin vinculación con una práctica funeraria.

La adscripción cronológica concreta de los materiales arqueológicos es problemática, ya que no los podemos fechar uno a uno de manera directa. Todos ellos son diagnósticos del denominado Bronce Inicial subdivisible, a su vez, en un Bronce Antiguo y un Bronce Medio.

Trab. Prehist., 74, N. ${ }^{\circ}$ 1, enero-junio 2017, pp. 149-167, ISSN: 0082-5638

doi: $10.3989 /$ tp.2017.12188 
El grupo epicampaniforme o "Grupo del Nordeste" (Martin et al. 2002; Maya y Petit 1995, 1986) ha servido para caracterizar el Bronce Antiguo, período tradicionalmente fechado entre el último tercio del III milenio y el primero del II (Maya 1997; Martín et al. 2002). Este grupo cerámico está definido por decoraciones realizadas mediante incisión y, a menudo también, punción de la superficie. Los motivos son guirnaldas y zigzags con flecos, esquematizaciones solares, temas espigados y bandas decorativas en líneas y puntos en la tradición decorativa del campaniforme regional aunque ya dentro de la Edad del Bronce. La mayoría se localizaron en yacimientos del área catalano-aragonesa, de ahí su denominación. En el Valle del Ebro y en Levante hay cerámicas similares (Maya y Petit 1986) por lo que en el futuro sería necesario ajustar más la denominación del grupo y profundizar en su repartición geográfica. Dicho esto, señalamos que la expresión "Grupo del Nordeste" se empleó para caracterizar el Bronce Antiguo (Maya 1997; Martin et al. 2002). Trabajos más recientes ubican este tipo de cerámicas entre el 2300 y el 1760 cal. BC (Barceló 2008) o entre el $\sim 2200$ y el 1650 cal. BC (Soriano 2013).

El Vaso 1 del nivel XXV de la Cova del Gegant con este tipo de decoración (Fig. 3.1) podría estar asociado a la datación obtenida para el nivel sepulcral, lo que alargaría todavía más ( 1600-1400 cal. BC) el rango cronológico de este tipo de cerámica. Caben dos hipótesis. Una es considerar varias fases en el osario con inhumaciones realizadas en la cronología radiocarbónica obtenida (3 de 19 individuos) y otras anteriores, menos frecuentes, que incluirían el vaso de estilo epicampaniforme. La segunda pasa por vincular este material con la cronología obtenida para el episodio funerario. Ello nos obligaría a considerar una perduración de este tipo de decoraciones más allá de lo actualmente admitido. A favor podríamos recordar la datación ${ }^{3}$ de la estructura 64 de El Pla del Serrador (3375 \pm 35 BP; 1753-1549 cal. BC) (Muñoz y Martínez 2012) o la procedente de la estructura II de la Escola Bressol l'Espiga (González y Harzbecher 2008) para la que se señala un marco cronológico de 1440-1310 cal.

\footnotetext{
${ }^{3}$ No se han publicados los datos sobre la datación, pero sabemos que se realizó por AMS sobre un hueso de cerdo doméstico (Pablo Martínez com. personal).
}

$\mathrm{BC}^{4}$. Ambas fechas están asociadas a cerámicas con decoración epicampaniforme y son posteriores al primer tercio del II milenio cal BC.

Los intentos para delimitar su marco cronológico (Maya y Petit 1995; Castro et al. 1996; Maya 1997; Martín y Mestres 2002; Barceló 2008; Soriano 2013) se han centrado en filtrar las fechas según su contexto de procedencia sin incidir en la propia naturaleza de la muestra. Gran parte de las que se consideran fiables se basan en carbones no identificados taxonómicamente. En un buen número han sido datados por método convencional que requiere $\sim 20-50 \mathrm{~g}$ de muestra, lo que implica la suma de varios carbones procedentes de un mismo nivel. Además las muestras sobre carbón pueden conllevar problemas de palimpsestos, infiltraciones postdeposicionales o elementos removilizados y requieren valorar el efecto "madera vieja" de algunas muestras. Las dataciones sobre huesos humanos disponibles tienen limitaciones análogas: algunas se han obtenido por el método convencional que requiere $200-400 \mathrm{~g}$ y/o a partir de varios huesos humanos, siendo imposible discernir si corresponden a uno o varios individuos (Castells y Enrich 1983). En este sentido, la Cova del Gegant podría aportar unas dataciones más precisas para el epicampaniforme, que tienden a rejuvenecerle. Sin embargo ya hemos comentado que la asociación entre estilo cerámico e individuos fechados sigue siendo problemática.

En referencia a los ornamentos, las cuentas circulares sobre material marino son frecuentes en el nordeste peninsular desde finales del III milenio y se contabilizan por decenas o centenares en los principales hipogeos, cuevas sepulcrales o sepulcros megalíticos ${ }^{5}$. La utilización de un revestimiento o pigmento de resina también tiene varios paralelos en el nordeste en yacimientos de cronología similar (Maya 1982; Castells and Enrich 1983) ${ }^{6}$ y también en el Languedoc (Constantini 1990). Las cuentas en ámbar o resina son también habituales en cronologías del Bronce Antiguo y

\footnotetext{
${ }^{4}$ No se han publicado más datos sobre esta datación y es imposible precisar el material fechado y si la calibración es a una o dos sigmas.

${ }^{5}$ Oliva, M. 2015: Aprofitament i transformació de matèries primeres per a l'elaboració d'ornaments durant la prehistòria recent (5600-3400 cal. ane) al nord-est de la península Ibèri$c a$. Tesis Doctoral inédita. Universitat Autònoma de Barcelona. Barcelona.

${ }^{6}$ Véase n. 5.
} 
Medio ${ }^{7}$. La mayoría parte de las piezas procedentes de contextos Calcolíticos y de la Edad de Bronce de la Península Ibérica podrían tener un origen exógeno (Rovira 1994), sin embargo, sin ser analizadas no se puede concretar. Menos habituales en estas cronologías son las cuentas de lignito, aunque las hay durante el Calcolítico (Petit 1977; Miquel y Morral 1980) y posteriormente durante el Bronce Antiguo (Pascual 1998) ${ }^{8}$.

La pieza lítica nos aporta muy poca información. Se corresponde con los denominados "dientes de hoz", un tipo de herramienta común en estos contextos. La mayoría no presentan los dos filos activos, sino solo uno con los extremos igualmente truncados y el filo opuesto modificado con un retoque abrupto para ser insertado en la hoz. Algunas piezas tienen los filos sin retocar y a medida que se embotan van volviéndose a afilar lo que les proporciona la delineación denticulada (Sarró 2000; Palomo et al. 2012; Esteve et al. 2015) .

Sin duda alguna, los dos tutuli de oro son lo más significativo del conjunto material. Los únicos paralelos en el nordeste peninsular son dos piezas de la Cova de les Pixarelles. Tienen un diámetro ligeramente mayor, un mayor estrechamiento de la parte central y una decoración mediante puntillado lineal de doble línea concéntrica (Rovira 1996). Ambas proceden de una excavación realizada por aficionados en los 1970 y posteriormente fueron asignadas al nivel X (nivel XIII de las excavaciones de los '70), intercalado entre los niveles VIII (Bronce Final) y XII (Bronce Inicial). El nivel X corresponde al Bronce Medio y dispone de dos dataciones sobre carbón no acelerado que se sitúan entre el $\sim 1400-1200$ cal BC (3150 $\pm 120 ; 1731-1060$ cal. BC y $2980 \pm 130$ BP; 1502-857 cal BC) (Rauret 1987; Mestres et al. 1991). Del mismo nivel proceden dientes de hoz, otro posible elemento de siega y dos objetos líticos más, una cuenta y un separador de ámbar $\mathrm{y}$ un fragmento de hacha de rebordes. No hay restos funerarios en la secuencia estratigráfica de Pixarelles que permitan vincular los tutuli con un nivel sepulcral ${ }^{9}$.

\footnotetext{
7 Véase n. 5.

8 Petit, M. A. 1974. Los objetos de adorno en los yacimientos eneolíticos de la Cataluña Oriental. Tesis de Licenciatura inédita. Universitat Autònoma de Barcelona. Barcelona.

9 Álvarez, R. 2001. Dinámica ocupacional de la cueva de Les Pixarelles (Tavertet, Osona). Tesis de Licenciatura inédita. Universitat de Barcelona. Barcelona.
}

Los demás paralelos peninsulares de los tutuli (Fig. 6) se diferencian de los de la Cova del Gegant por tener una o varias perforaciones y se han recuperado tanto en depósitos como en contextos funerarios o habitacionales. De los 35 adornos de oro del tesorillo del Cabezo Redondo, 10 son tutuli. En el asentamiento se recuperaron 4 más: dos en contextos funerarios (Hernández Pérez 1997; Simón 1998) y dos en habitacionales, uno de los cuales tiene una fecha asociada de $\sim 1350$ cal. BC (3080 \pm 60 BP; 1496-1132 cal $\mathrm{BC}{ }^{10}$ (Hernández Pérez 2012; Jover Maestre et al. 2014), acorde con la cronología del yacimiento ( 1500-1250 cal. BC) situado en el Bronce Tardío. En el caso del Tesorillo, dada su similitud tipológica (Hernández Pérez et al. 2014), podrían corresponder al mismo momento que el asentamiento. Hay algún otro ejemplar que podría ser de la misma época, como el de la Cuesta del Negro (Purullena, Granada) que se asocia a Cogotas I (Molina y Pareja 1975). La cronología de los 13 restantes es imprecisa (Perea 1991). Dos provienen de la Cueva de Jórox (Málaga), tres de la necrópolis de cistas de El Castañuelo (Huelva) (Perea 1991; Perea et al. 2010) y dos del interior de una de las tumbas megalíticas de Murviedro (Lorca, Murcia), recuperadas durante una intervención de salvamento tras la acción de furtivos (Idáñez 1985). Completan el conjunto los seis recuperados en el yacimiento portugués de Sâo Martinho durante labores agrícolas en 1910 (Heleno 1935). Finalmente señalamos que los adornos hiperbólicos de oro y plata de los contextos agáricos, a diferencia de los tutuli, están abocinados en ambos lados.

La decoración puntillada lineal tiene también paralelos en el nordeste peninsular (Soriano 2013). En una diadema de la Cova de Montanissell una profusa decoración conforma dos motivos idénticos y opuestos asimilados con un antropomorfo esquemático. Las 7 dataciones de la cavidad se sitúan en la horquilla $\sim 1550-1400$ cal. BC (Armentano et al. 2014, 2007), parecida a la de la Cova del Gegant. Encontramos de nuevo esta decoración en la aguja metálica de cabeza discoidal procedente de la Cova del Toll. Carece de contexto pero su tipología la situaría en el mismo momento (Petit 2001).

${ }^{10}$ Véase n. 2.

Trab. Prehist., 74, N. ${ }^{\circ}$ 1, enero-junio 2017, pp. 149-167, ISSN: 0082-5638

doi: $10.3989 /$ tp.2017.12188 


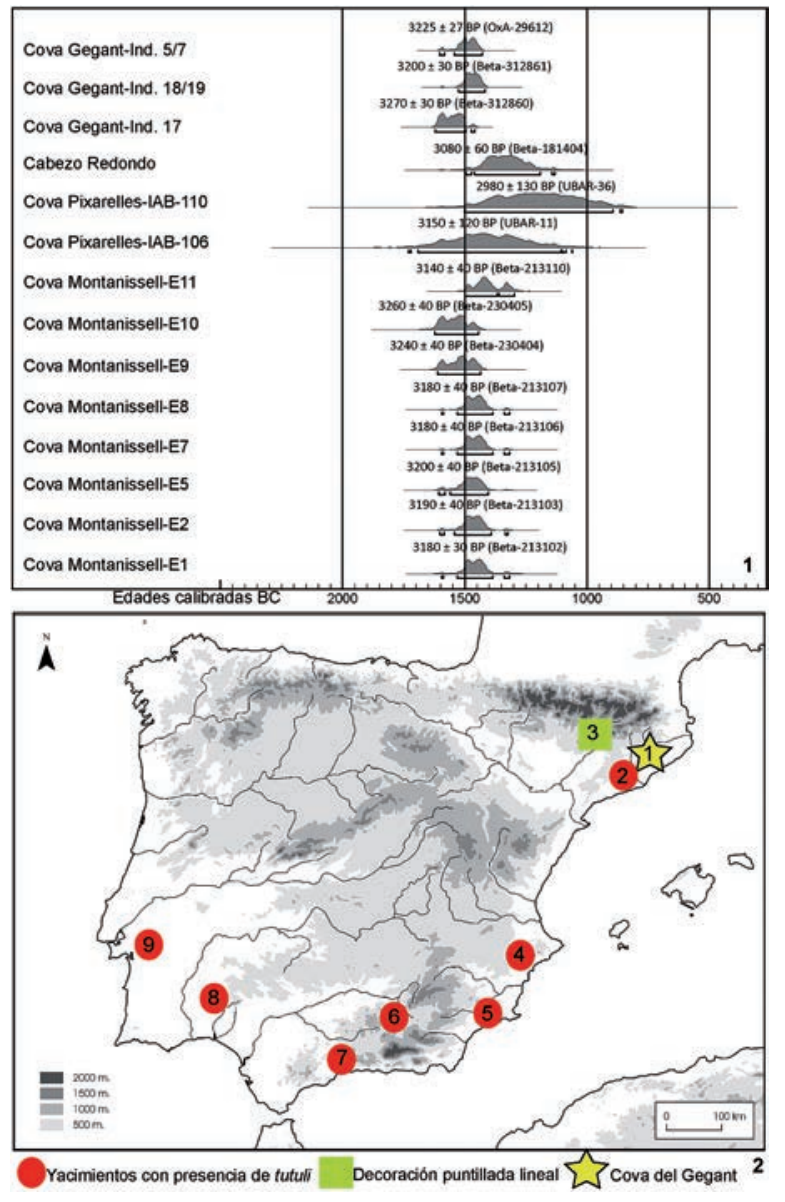

Fig. 6. Relación de los tutuli de la Cova del Gegant (Sitges, Barcelona) con las principales localidades que presentan estos elementos y semejanzas decorativas. 1: Dataciones calibradas (Armentano et al., 2014; Jover Maestre et al., 2014; Mestres et al., 1991) de los yacimientos que presentan tutuli en la Península Ibérica y decoración puntillada lineal en el NE. 2: Distribución de los principales tutuli documentados en la Península Ibérica. 1. Cova de les Pixarelles; 2. Cova del Gegant; 3. Cova de Montanisell; 4. Cabezo Redondo; 5. Tumba megalítica de Murviedro; 6. Cuesta del Negro; 7. Cueva de Jórox; 8. Cistas de El Castañuelo; 9. São Martinho.

Los datos expuestos nos permiten plantear tres observaciones sobre los tutuli. Las piezas catalanas y, en especial, el par de la Cova del Gegant son ligeramente más antiguas que las del Levante. Ello es de gran interés para establecer el origen y dispersión de este tipo de ornamentos. En segundo lugar el contexto de hallazgo de algunos y sus similares características (dimensiones, decoración, número de perforaciones) les emparejan. Así se observa en los cuatro del Nordeste y de otras zonas peninsulares aunque no de todas. Ello apunta a la fabricación y uso conjunto de los tutuli, al menos en un número importante de casos, desconociendo si formaban parte de un único adorno o de dos combinados. En tercer lugar es difícil determinar si implica una producción local el que los tutuli de Cova del Gegant y su decoración sean algo más antiguos que adornos anólogos del resto de la Península Ibérica. Si el tutulus sin decoración ni pulido final estuviera inacabado, sería poco probable que las fases de fabricación de estos adornos corrieran a cargo de personas distintas y en varios lugares. Como los restantes objetos decorados con la técnica puntillada son excepcionales y cuentan con paralelos conocidos en otros territorios europeos, no se excluye una producción foránea (Soriano 2013). En el nordeste de la Península Ibérica se conocen criaderos auríferos (Lehrberger 1995; Martín et al. 1999). Los más cercanos a la Cova del Gegant están a $~ 55 \mathrm{~km}$ en la Garriga y en Cama d'Or, pero no pueden aprovecharse al ser mineralizaciones primarias y no placeres (Martín et al. 1999). El placer más cercano está en el río Tordera $(\sim 100 \mathrm{~km})$ y el resto mucho más alejados en los ríos Ebro, Segre, Noguera Pallaresa, Noguera Ribagorçana, Muga-Orlina y Ter (Viladevall et al. 1991). Por desgracia la falta de datos sobre la composición isotópica de estas y otras posibles áreas de captación de oro en la Península Ibérica impide probar fehacientemente el origen de los objetos arqueológicos.

\section{CONCLUSIÓN}

Los materiales procedentes de la Cova del Gegant son relevantes por si mismos y porque nos aproximan a aspectos como las relaciones entre el nordeste de la Península Ibérica y sus territorios vecinos. La presencia de objetos de oro en el Nordeste se limita, casi en exclusiva, al Neolítico Final-Calcolítico, es decir, al final del IV milenio cal. BC. Aumenta ostensiblemente a partir del Calcolítico Reciente, ya vinculada al grupo Campaniforme. Se trata siempre de adornos (cuentas y apliques) de dimensiones reducidas y tipología diversa (Rovira Hortalà et al. 2005; Soriano et al. 2012). Durante la Edad del Bronce estos objetos desaparecen casi en su totalidad (Soriano 2013). 
Las piezas de la Cova del Gegant y, probablemente, las de la Cova de les Pixarelles son las únicas con contexto seguro.

El vaso geminado con decoración epicampaniforme del "Grupo del Nordeste" hallado en Cova Verda, un yacimiento cercano a Cova del Gegant ( $\sim 70 \mathrm{~m}$ ), es un dato muy interesante (Petit y Rovira 1980). La sincronía entre este tipo de decoración y los vasos geminados ha sido frecuentemente apuntada cuando se constatan las estrechas relaciones entre el Nordeste y Levante de la Península Ibérica durante la Edad del Bronce. De forma sintética, en el Levante se localiza el origen de tipos y técnicas cerámicas detectados en el Nordeste como los vasos geminados, con cazoleta interna y con impronta de estera. A su vez, desde el Nordeste, ciertos adelantos tecnológicos vinculados con la metalurgia (moldes para puñales, crisoles con sistema de prensión, aleación en bronce), así como la ya citada decoración epicampaniforme habrían alcanzado algunos yacimientos levantinos (Soriano y Amorós 2014a, 2014b; Soriano y Escanilla 2016). En este marco de interacciones regionales se debe interpretar la similitud entre los apliques de oro catalanes (Cova del Gegant y Cova de les Pixarelles) y levantinos (Cabezo Redondo). La ligera mayor antigüedad de los ejemplares de Cova del Gegant podría apuntar hacia una probable difusión hacia el Levante junto al resto de elementos cerámicos y metalúrgicos citados, siempre teniendo en cuenta que el volumen de oro en el Nordeste es inferior al del Levante.

\section{AGRADECIMIENTOS}

J. Daura ha contado con un contrato posdoctoral (SFRH/BPD/100507/2014) a cargo de la Fundação para a Ciência e a Tecnologia (Portugal) con la financiación del FSE/POPH y M. Sanz con un contrato Juan de la Cierva (FJCI-2014-21386).

\section{BIBLIOGRAFÍA}

Agustí, B. y Mercadal, O. 2002: "Rituals funeraris i antropologia entre el neolític final i l'edat del bronze inicial en el marc català i els territoris veïns". En XII Col-loqui Internacional d'Arqueologia Puigcerdà.
Pirineus $i$ veïns al tercer mil·leni AC (Puigcerdà 2000): 591-642. Puigcerdà.

Alemán, I.; Botella, M. C. y Ruiz, L. 1997: “Determinación del sexo en el esqueleto postcraneal. Estudio de una población mediterránea actual". Archivo Español de Morfología 2: 69-79.

Armentano, N.; Gallart, J.; Jordana, X.; López, J. B.; Malgosa, A. y Rafel, N. 2007: "La Cova sepulcral de Montanissell (Sallent-Coll de Nargó, Alt Urgell): pràctiques funeràries singulars durant l'edat del bronze al Prepirineu". Tribuna d'Arqueologia 2006: 147-167.

Armentano, N.; Jordana, X. y Malgosa, A. 2014: "Estudio tafonómico e interpretación del gesto funerario de los restos óseos de la Cova de Montanissell (Alt Urgell, Lleida)". Trabajos de Prehistoria 71: 156-172.

Armentano, N. y Malgosa, A. 2003: "Enterramientos primarios versus enterramientos secundarios". Actas del XII Congreso de la Sociedad Española de Antropología Biológica (Barcelona 2001). Antropología y Biodiversidad: 39-49. Barcelona.

Barceló, J. A. 2008: "La seqüència crono-cultural de la prehistòria catalana. Anàlisi estadística de les datacions radiomètriques". Cypsela 17: 65-88.

Bronk Ramsey, C. 2009: "Bayesian analysis of radiocarbon dates". Radiocarbon 51: 337-360.

Brothwell, D. R. 1989: "The relationship of tooth wear to aging”. En M. Y. Iscan (ed.): Age Markers in the Human Skeleton. CC. Thomas Publisher. Springfield, Illinois: 303-316.

Capuzzo, G. y Barceló, J. A. 2015: “Cultural changes in the second millennium BC: a Bayesian examination of radiocarbon evidence from Switzerland and Catalonia". World Archaeology 47: 622-641.

Castells, J. y Enrich, J. 1983: "Túmul I de la Serra de Clarena. Una inhumació col·lectiva”. Tribuna d'Arqueologia 1982-1983: 79-84.

Castro, P. V.; Lull, V. y Mico, L. R. 1996: Cronología de la Prehistoria Reciente de la Península Ibérica y Baleares (c. 2800-900 cal ANE). British Archaeological Reports, International Series 652, Archaeopress. Oxford.

Constantini, G. 1990: "Chalcolithique". En Musée Archéologique de Montrozier (ed.): Parures, Bijoux et Accessoires dans l'archéologie aveyronnaise, du Néolithique au XVIIe siècle. Guides d'Archéologie 1, Musée du Rouergue, Averyon: 24-45.

Daura, J.; Sanz, M.; Pike, A. W. G.; Subirà, M. E.; Fornós, J. J.; Fullola, J. M.; Julià, R. y Zilhão, J. 2010: "Stratigraphic context and direct dating of the Neandertal mandible from Cova del Gegant (Sitges, Barcelona)". Journal of Human Evolution 59: 109-122.

Dedet, B. y Py, M. 1975: Classification de la céramique non tournée protohistorique du Languedoc méditerranéen. Revue Archéologique de Narbonnaise, supplément 4. Paris. 
Esteve, X.; Armentano, N.; Espejo, J. M.; Gallart, J.; Gibaja, J. F.; López, D.; Mangado, X.; Marín, D.; Nadal, J. y Oms, F. X. 2015: "El Pla de Tabac I (Montoliu de Lleida), un assentament de l'edat del bronze a la Plana de Lleida". Revista d'Arqueologia de Ponent 25: 137-168.

González, J. y Harzbecher, K. 2008: "Nova intervenció arqueològica al turó de can Filuà. un espai domèstic del bronze inicial a l'escola bressol municipal l'Espiga". L'Ordit, l'anuari del Centre de Recerques i Estudis Mogoda 2: 73-85.

Heleno, M. 1935: "Joias pré-romanas". Ethnos 1: 229257.

Hernández Pérez, M. 1997: "Desde la periferia de El Argar: la Edad del Bronce en las tierras meridionales valencianas". Saguntum (PLAV) 30: 93-114.

Hernández Pérez, M. 2012: "El Cabezo Redondo (Villena, Alicante) y el Bronce Tardío en las tierras meridionales valencianas". En J. A. Rodríguez Marcos y J. Fernández Manzano (eds.): Cogotas I: Una Cultura de la Edad del Bronce en la Península Ibérica: Homenaje a M. ${ }^{a}$ Dolores Fernández-Posse. Serie Arte y Arqueología 30, Universidad de Valladolid. Valladolid: 111-146.

Hernández Pérez, M.; García Atiénzar, G. y Barciela González, V. 2014: "The treasures of Villena and Cabezo Redondo (Alicante, Spain)". En H. Meller, R. Risch y E. Pernicka (eds.): Metals of power Early gold and silver. $6^{\text {th }}$ Archaeological Conference of Central Germany (Halle, Saale 2013). Tagungen des Landesmuseum für Vorgeschichte Halle 11/2, Landesamt für Denkmalpflege und Archäologie Sachsen-Anhalt. Halle: 593-609.

Idáñez, J. 1985: "Yacimiento eneolítico de Murviedro (Lorca)". Revista de Arqueología 53: 60-61.

Işcan, M. Y.; Loth, S. R. y Wright, R. K. 1984: “Age estimation from the rib by phase analysis: white males". Journal of Forensic Science 29: 1094-1104.

Işcan, M. Y.; Loth, S. R. y Wright, R. K. 1985: "Age estimation from the rib by phase analysis: white females". Journal of Forensic Science 30: 853-863.

Jover Maestre, F. J.; López Padilla, J. A. y García-Donato Layrón, G. 2014: "Radiocarbono y estadística Bayesiana: aportaciones a la cronología de la Edad del Bronce en el extremo oriental del sudeste de la península Ibérica". Saguntum (PLAV) 46: 41-69.

Jurado-López, A.; Luque de Castro, M. D. y PérezMorales, R. 2006: "Application of energy-dispersive $\mathrm{X}$-ray fluorescence to jewellery samples determining gold and silver". Gold Bulletin 39: 16-21.

Lehrberger, G. 1995: "The gold deposits of Europe: an overview of the possible metal sources for prehistoric gold objects". En G. Morteani y J. P. Northover (eds.): Prehistoric gold in Europe: mines, metallurgy and manufacture. Springer. Netherlands: 115-144.

Lull, V.; Micó, R.; Rihuete Herrada, C.; Risch, R.; Celdrán Beltrán, E.; Fregeiro Morador, M. I.; Oliart Caravatti, C. y Velasco Felipe, C. 2015: La Almoloya
(Pliego, Murcia). Ruta Argárica. Guías Arqueológicas 2, Ed. Integral, Sociedad Para el Desarrollo Rural. Bullas, Murcia.

Martín, A.; Gallart, J.; Rovira Hortalà, M. C. y MataPerelló, J. M. 1999: "Nordeste”. En G. Delibes y I. Montero (eds.): Las primeras etapas metalúrgicas de la Península Ibérica II. Estudios regionales. Instituto Universitario Ortega y Gasset. Madrid: 115-177.

Martín, A. y Mestres, J. S. 2002: "Periodització des de la fi del neolític fins a l'edat del bronze a la Catalunya sud-pirinenca. Cronologia relativa i absoluta". En XII Col·loqui Internacional d'Arqueologia Puigcerdà. Pirineus $i$ veïns al tercer mil-leni $A C$ (Puigcerdà 2000): 77-130. Puigcerdà.

Martin, A.; Petit, M. À. y Maya, J. L. 2002: “Cultura material, economia i intercanvis durant el III millenni AC a Catalunya". En XII Col·loqui Internacional d'Arqueologia Puigcerdà. Pirineus $i$ vë̈ns al tercer mil·leni AC (Puigcerdà 2000): 10-12. Puigcerdà.

Martínez-Moreno, J.; Mora, R.; Muro, I. y Miret, J. 1985. Memòria de l'excavació d'urgència de la cova del Gegant (Sitges, Garraf) 1985. Servei d'Arqueologia i Paleontologia. Centre d'Informació i Documentació del Patrimoni Cultural de la Generalitat de Catalunya, Barcelona.

Martínez-Moreno, J.; Mora, R.; Roca, G. y Parcerisas, J. 1990. Memòria d'excavació a la cova del Gegant 1989. Servei d'Arqueologia i Paleontologia. Centre d'Informació i Documentació del Patrimoni Cultural de la Generalitat de Catalunya, Barcelona.

Maya, J. L. 1982: "Asentamientos al aire libre de la Edad del Bronce en la Cataluña Occidental. Bases para el reconocimiento de un horizonte Bronce Antiguo-Reciente". Ilerda 43: 153-186.

Maya, J. L. 1997: "Reflexiones sobre el Bronce inicial en Cataluña". Saguntum (PLAV) 30: 11-27.

Maya, J. L. y Petit, M. A. 1986: "El grupo del Nordeste: un nuevo conjunto de cerámicas con boquique en la Península Ibérica". Anales de Prehistoria y Arqueología 2: 49-72.

Maya, J. L. y Petit, M. A. 1995: “L'Edat del Bronze a Catalunya. Problemàtica i perspectives de futur". En X Col-loqui Internacional d'Arqueologia de Puigcerdà: Cultures $i$ Medi. De la Prehistòria de L'edat Mitjana (Puigcerdà 1994): 327-342. Puigcerdà.

Mestres, J.; Rauret, A. M. y Gracia, J. F. 1991. "University of Barcelona radiocarbon dates I". Radiocarbon 33: 355-365.

Miquel, D. y Morral, E. 1980: "L'enterrament col-lectiu de Can Vinyals (Santa Perpètua de Mogoda)". Arraona Revista d'Història 10: 26-36.

Molina, F. y Pareja, E. 1975. Excavaciones en la Cuesta del Negro (Purullena, Granada). Campaña de 1971. Excavaciones Arqueológicas de España 86, Ministerio de Cultura. Madrid.

Montero, I. y Rovira, S. 1991: "El oro y sus aleaciones en la orfebrería prerromana". Archivo Español de Arqueología 64: 7-21. 
Muñoz, V. y Martínez, P. 2012: “L'estudi dels materials ceràmics prehistòrics del Pla del Serrador (Les Franqueses del Vallès, Vallès oriental)". Cypsela 19: 159-178.

Murillo-Barroso, M.; Eleazar Costa, M.; Díaz-Guardamino, M.; García Sanjuán, L. y Mora, C. 2015: “A reappraisal of Iberian Copper Age goldwork: craftmanship, symbolism and art in a non-funerary gold sheet from Valencina de la Concepción". Cambridge Archaeology Journal 25: 565-596.

Palomo, A.; Gibaja, J. F.; Ortega, D.; Alonso, N.; Marín, D. y Moya, A. 2012: "La industria lítica tallada del asentamiento de Minferri (Juneda, Lleida) a finales del III/primera mitad del II milenio cal. BC". Cypsela 19: 103-122.

Pascual, J. L. 1998: "Las fuentes de materia prima de los adornos de lignito prehistóricos de la vertiente mediterránea peninsular entre el Ebro y el Segura”. En Actes de La 2a Reunió de treball sobre aprovisionament de recursos lítics a la Prehistòria. Rubricatum: revista del Museu de Gavà: 153-160.

Perea, A. 1991: Orfebrería prerromana: arqueología del oro. Exposición, Casa del Monte, Madrid, julioagosto 1991. Comunidad de Madrid, Dirección General de Patrimonio Cultural. Madrid.

Perea, A.; García Vuelta, O. y Fernández Freire, C. 2010: "El proyecto Au: estudio arqueométrico de la producción de oro en la península Ibérica". Bibliotheca Praehistorica Hispana XXVII, CSIC. Madrid.

Pernicka, E. 2014a: "Provenance Determination of Archaeological Metal Objects". En B. W. Roberts y C. P. Thornton (eds.): Archaeometallurgy in global perspective: methods and syntheses. Springer New York. Nueva York: 239-268.

Pernicka, E. 2014b: "Possibilities and limitations of provenance studies of ancient silver and gold". En H. Meller, R. Risch y E. Pernicka (eds.): Metals of power - Early gold and silver. $6^{\text {th }}$ Archaeological Conference of Central Germany (Halle, Saale 2013). Tagungen des Landesmuseum für Vorgeschichte Halle 11/1, Landesamt für Denkmalpflege und Archäologie Sachsen-Anhalt. Halle:153-164.

Petit, M. A. 1977: “Objetos de adorno de lignito en el calcolítico catalan". En XIV Congreso Arqueológico Nacional (Vitoria 1975), vol XIII. Universidad de Zaragoza, Seminario de Arqueplogia: 325-332.

Petit, M. A. 2001: "El Toll: resultats dels treballs de condicionament de l'any 1985". Modilianum 24: 53-66.

Petit, M. A. y Rovira, J. 1980: El jaciment arqueològic de la Cova Verda $i$ alguns problemes del Neolític i l'edat de Bronze a Catalunya. Quaderns de Treball 3, Institut de Prehistòria i Arqueologia de la Diputació de Barcelona, Dept. de Prehistòria i Arqueologia de la Universitat Autònoma de Barcelona. Barcelona.

Raub, C. J. 1995: "The metallurgy of gold and silver in prehistoric times". En G. Morteani y J. P. Nor- thover (eds.): Prehistoric gold in Europe: mines, metallurgy and manufacture. Springer, Netherlands: 243-259.

Rauret, A.M. 1987: "La seqüència estratigràfica de la Cova de les Pixarelles (Tavertet, Osona)". Tribuna d'Arqueologia 1986-1987: 59-68.

Reimer, P. J.; Bard, E.; Bayliss, A.; Beck, J. W.; Blackwell, P. G.; Bronk Ramsey, C.; Buck, C. E.; Cheng, H.; Edwards, R. L.; Friedrich, M.; Grootes, P. M.; Guilderson, T. P.; Haflidason, H.; Hajdas, I.; Hatté, C.; Heaton, T. J.; Hoffmann, D. L.; Hogg, A. G.; Hughen, K. A.; Kaiser, K. F.; Kromer, B.; Manning, S. W.; Niu, M.; Reimer, R. W.; Richards, D. A.; Scott, E. M.; Southon, J. R.; Staff, R. A.; Turney, C. S. M. y van der Plicht, J. 2013: "IntCal13 and Marine13 radiocarbon age calibration curves 0-50,000 years cal BP”. Radiocarbon 55: 1869-1887.

Roessiger, V. y Nensel, B. 2003: "Non destructive analysis of gold alloys using energy dispersive x-ray fluorescence analysis". Gold Bulletin 36: 125-137.

Rovira, J. 1994: “Ámbar y pasta vítrea. Elementos de prestigio entre el Neolítico avanzado y el Bronce final del nordeste de la península ibérica. Un primer estado de la cuestión". Quaderns de Prehistòria $i$ Arqueolologia de Castelló 16: 67-92.

Rovira, J. 1996: "El conjunto de elementos en oro y bronce de la cueva de les Pixarelles (Tavertet, Cataluña). Reflexiones sobre la producción y el comercio de objetos suntuarios y ornamentales a lo largo de la Edad del Bronce en el Noreste de la Península Ibérica". En T. Chapa y M. A. Querol (eds.): Homenaje al profesor Manuel Fernández-Miranda. Complutum Extra 6, 1, Universidad Complutense. Madrid: 171-178.

Rovira Hortalà, M. C.; Borrell, F.; Oliva, M.; Saña, M.; Vicente, O. y Casellas, S. 2005: "Las primeras manufacturas de oro en Catalunya: nuevos datos procedentes del yacimiento de La Prunera (Girona)". En O. Puche y M. Ayarzagüena (eds.): Minería y metalurgia históricas en el sudoeste europeo (Madrid 2004): 53-60. Madrid.

Sarró, E. 2000: 'Les Roques del Sarró (Lleida, Segrià): evolució de l'assentament entre el 3600 cal. ane i el i el 175 ane [PART 1]'. Revista d'Arqueologia de Ponent 10: 103-124.

Schaefer, M.; Black, S. M. y Scheuer, L. 2009: Juvenile osteology: a laboratory and field manual. Academic Press. London.

Simón, J. L. 1998: La metalurgia prehistórica valenciana. Diputación de Valencia. Valencia.

Soler García, J. M. 1987: Excavaciones arqueológicas en el Cabezo Redondo (Villena, Alicante). Instituto Juan Gil-Albert. Alicante.

Soriano, I. 2013: Metalurgia y sociedad en el Nordeste de la Península Ibérica:(finales del IV-II milenio cal $A N E)$. British Archaeological Reports, International Series 2502, Archaeopress. Oxford. 
Soriano, I. y Amorós, J. 2014a: "El vaso geminado de Camp Cinzano (Vilafranca del Penedès, Barcelona) y las relaciones nordeste-levante-Valle del Ebro durante la Edad del Bronce". Revista d'Arqueologia de Ponent 24: 9-25.

Soriano, I. y Amorós, J. 2014b: “Moldes para puñales en la Península Ibérica durante la Edad del Bronce. El caso de Camp Cinzano (Vilafranca del Penedès, Alt Penedès, Barcelona)". Trabajos de Prehistoria 71: 368-385.

Soriano, I. y Escanilla, N. 2016: "Can Mur (Barcelona). Crisoles con sistema de prehensión y la metalurgia de la Edad del Bronce en el Nordeste de la Península Ibérica". Trabajos de Prehistoria 73: 160-179.

Soriano, I.; Soler, J. y Soler, N. 2012: “¿La primera orfebrería del nordeste de la Península Ibérica? Nuevas aportaciones a partir de la cuenta áurea de Cau del Tossal Gros (Torroella del Montgrí, Baix Empordà, Girona)". Trabajos de Prehistoria 69: 149-161.
Ubelaker, D. H. 1978: Human skeletal remains: excavation, analysis, interpretation. Aldine Publishing Company. Chicago.

Vega, J. de la 1987: “Contribució catalana al inventari de les probables coves santuari ibèriques". Fonaments 6: 171-190.

Viciano, J.; López-Lázaro, S. y Alemán, I. 2013: "Sex estimation based on deciduous and permanent dentition in a contemporary Spanish population". American Journal of Physical Anthropology 152: 31-43.

Viladevall, M.; Camacho, G.; Marturia, J. y Ponce, J. M. 1991: "Los placeres auríferos de la llanura aluvial del río Segre y delta del río Ebro (NE de la Península Ibérica)". En G. Hérail y M. Fornari (eds.): Symposium international sur les gisements alluviaux d'or (La Paz 1991): 187-215. La Paz, Bolivia.

Ward, G. K. y Wilson, S. R. 1978: "Procedures for comparing and combining radiocarbon age determinations: a critique". Archaeometry 20: 19-31. 